\title{
Sobre restaurar fios: reflexões sobre a pobreza em A hora da estrela
}

Ivana Ferrante Rebello ${ }^{1}$

"Por que escrevo sobre uma jovem que nem pobreza enfeitada tem?" (Lispector, 1984, p. 27). A pergunta do autor-narrador Rodrigo S. M., na parte introdutória do romance $A$ hora da estrela, revolve uma linha de escrita literária no Brasil que elegeu a pobreza como tema, como o comprovam as obras de Lima Barreto, Graciliano Ramos, João Cabral de Melo Neto, Rachel de Queiroz, Guimarães Rosa e tantos outros.

O estudo das relações entre o processo histórico-social e as manifestações artísticas na literatura evidencia as contribuições do discurso literário, com suas peculiaridades, para o fornecimento de subsídios, e de todo um complexo arcabouço de percepções e imagens, para o conhecimento da estrutura dinâmica na sociedade.

É sabido que a literatura é constantemente desafiada pelas questões sociais e que, de posse do desafio de escrever sobre a sociedade, ela desestabiliza as engrenagens que sustentam o mundo, movimentando a aparente fixidez dessas estruturas e questionando a ordem vigente. Ao construir tipos e personagens, cenas e paisagens, a literatura instaura um movimento de autoconsciência e desvelamento. O leitor, ao traduzir o dito e, às vezes, a desdita do personagem, acabam por sonorizar, movimentar e tensionar a escrita, abrindo suportes para a elucidação de valores, ainda que tal elucidação não seja o correlato de explicar ou de consertar. O que se considera como inquestionável bem da literatura é a apropriação dos vários discursos, culturas, historicidades e etnias que promovem imaginações, debates e reflexões, capazes de desorganizar a aparente organização da máquina social e fazer intuir sobre novas relações.

Nesse sentido, a pergunta lançada por Rodrigo S. M. reverbera para além do próprio texto, lançando ao leitor questões sobre a literatura de Clarice Lispector e sobre as inúmeras proposições acerca da pobreza que a escrita de A hora da estrela pode suscitar.

A hora da estrela é o último livro escrito por Clarice Lispector. Foi publicado em 1977, no vigor da ditadura militar brasileira, sob a iminência da Crise do Petróleo e de várias crises do mundo capitalista, e poucos meses antes da morte da escritora. A personagem Macabéa - aquela que não tem

${ }^{1}$ Doutora em Literaturas de Língua Portuguesa, professora titular da Universidade Estadual de Mon-
tes Claros (Unimontes), Montes Claros, Minas Gerais, Brasil. E-mail: ivanaferrante@hotmail.com 
a pobreza enfeitada - é personagem excêntrica, em se recorrendo ao sentido mais denotativo do termo, na literatura de Clarice Lispector.

O universo feminino, escrito na sensibilidade das entranhas que, conforme se sabe, constitui a marca autoral de Clarice Lispector, cede espaço a uma escrita diferente, pretensamente objetiva e neutra; o mais próxima possível daquilo que o próprio narrador do romance qualificará como "trabalho manual" (Lispector, 1984, p. 26). A história da datilógrafa nordestina vivendo na cidade grande é, de fato, uma matéria bruta, de artefato manual, pura e rude como quer a autora. Por um lado, ao menos explicitamente, faltam o retoque e o apelo ao sublime, usuais na sua escrita, mas, por outro lado, sobram culpas, tensões e críticas.

Os livros de Clarice Lispector estão repletos de imagens que falam de uma apreensão do dia a dia, de um pensar fragmentado entre tarefas, da ordem e da desordem, em sucessão de movimentos, corrompendo a rotina da vida. Nesse universo, Macabéa é uma personagem solitária no universo das mulheres clariceanas, no qual se destacam as donas de casa, as mães e as meninas - mulheres sempre por um triz dentro da sociedade limitadora, tendo, de repente, o cotidiano claustrofóbico que as aprisiona perfurado por uma atordoante lucidez. Refiro-me aos momentos em que essas mulheres suspendem a mão que trabalha, sugerindo que o pensamento está em outro lugar; mulheres que se desligam momentaneamente do fazer, para deixar aflorar o ser; momentos de mulheres imersas na tarefa comezinha, corriqueira, no espaço social restrito que lhes coube, que, repentinamente, mostram-se alheias a tudo. Caberia, nesse intervalo da dona de casa comum, a ousadia de uma possível metafísica do instante?

Nesse universo denso, Macabéa provoca-nos justamente por sua precariedade em existir. Essa precariedade é construída pela imagem da pobreza, reiterada por toda a narrativa, numa redundância de significados que levam o sentido do termo ao extremo. Como suporte às reflexões aqui apresentadas, recobro a definição de pobreza dada por Joel Rufino dos Santos, para quem os pobres

são os desprezíveis, não de qualquer posse, mas de território, de casa, de emprego (embora não de trabalho), de local (embora não de lugar), de família (embora não de nome) e enfim, do próprio corpo (no caso de escravos e servos da Colônia ou Império). São, em suma, um estado nômade ou vagabundo (Santos, 2004, p. 29).

Para Santos, a definição do pobre como excluído deve ser questionada, uma vez que o pobre, na verdade, está incluído nessa situação de penúrias e de dificuldades. O termo "excluído" omitiria uma situação real que é a exploração econômica, a maior responsável pela pobreza. Além disso, é 
fato que o governo ou a sociedade civil não excluem o pobre, uma vez que é ele, o pobre, quem se sujeita às mais terríveis condições de trabalho. Esse quadro de exploração é bem tipificado pela datilógrafa Macabéa, que lidava mal e parcamente com as letras que não conhecia, pela relação com o patrão que a ofendia e desprezava, embora a mantivesse no emprego, porque ela fora a única que aceitara trabalhar por menos de um salário mínimo. Há, pois, uma aguda consciência perfurando, como uma agulha a um tecido esgarçado, a escrita dessa história.

É exigida da escritora uma tarefa de depuração às avessas, que lhe pede para livrar-se de certos artifícios da linguagem a fim de dar corpo à narrativa. Em tal processo, a criação de um autor masculino é decisiva: é preciso distanciar-se para encontrar-se. Na cara barbada de Rodrigo está Macabéa, está Clarice, e uma condição de pobreza e tensão que os iguala: Vejo a nordestina se olhando ao espelho e - um ruflar de tambor - no espelho aparece o meu rosto cansado e barbudo. Tanto nós nos intertrocamos. Não há dúvida de que ela é uma pessoa física. [...] É que de repente o figurativo me fascinou: crio a ação humana e estremeço. Também quero o figurativo assim como o pintor que só pintasse cores abstratas quisesse mostrar que o fazia por gosto, e não por não saber desenhar (Lispector, 1984, p. 29).

É um jogo especular que se cria, capaz de projetar criador e criatura(s) em imagens que se provocam, a ponto de o leitor desconfiar sobre quem se olha efetivamente ao espelho; afinal, no início do romance, a própria Clarice confessa sua autoria, mas é Rodrigo quem fala, no texto.

Ao mencionar sua opção pelo figurativo, Rodrigo (Clarice) deixa escapar uma sutil ironia sobre o fingimento de uma objetividade realista que se comprovará absurda e inócua, no decorrer da narrativa. De certa forma, soa como resposta da escritora aos que a criticam por se furtar de uma literatura de cunho mais social, que fale mais dos problemas emergentes do povo e menos das questões existenciais. Quando o livro A hora da estrela é lançado no Brasil, a crítica o elogia, afirmando que, ao enveredar pela "coisa social", Clarice apresenta, enfim, uma literatura menos hermética. Mas nem todos se deixam enganar por essa aparente simplificação:

Agora com este livro publicado, $A$ hora da estrela, seria ridículo afirmar que Clarice Lispector sucumbiu às pressões para que escrevesse um livro "em defesa dos oprimidos" ou que ela aceitasse o desafio absurdo de "provar" que é capaz de escrever sobre os seres que só existem nas estatísticas populacionais, como o naturalista Zola "provou" ser capaz de criar voluntariamente uma obra romântica. 
Ivana Ferrante Rebello

Não. A raiz oculta de $A$ hora da estrela está em qualquer de seus contos ou romances (Ribeiro, 1977, p. 19).

Na verdade, Clarice está evidenciando - com estratégias de que só ela faz uso - que tudo perpassa pelo olhar ao espelho. É a ausência de sentidos para a existência, ou a impossibilidade de perscrutá-los, que fomenta a pobreza, a fome, a exploração. Assim, para escrever sobre a mulher Macabéa, ela se despe da sua própria condição de mulher e da sua escrita autoral; ela suspende a abstração em nome da ação, no entanto, estes são artifícios que denunciam, no fundo das imagens do espelho, as mesmas inquietações e rasuras de sempre.

É interessante pontuar que criar Macabéa, a personagem inteiramente despossuída, requer que a autora adote, uma a uma, uma série de práticas de negação: primeiramente, afastando-se da voz autoral, constituindo uma fala masculina para seu texto; depois, tentando se despojar de sentimentos, desejos, emoções, como nos confessa na página inicial do seu romance: "Meu coração se esvaziou de todo desejo" (Lispector, 1984, p. 17); finalmente, deixa de fazer a barba, de dormir, de tomar banho. E o narrador adverte o leitor de um sentido que é fundamental à leitura do romance: "Mas desconfio que toda essa conversa é feita apenas para adiar a pobreza da história, pois estou com medo" (Lispector, 1984, p. 23). Essa advertência diz mais do que podemos prever: trata-se de uma história que tematiza a pobreza; trata-se de uma história que traz em si a pobreza; trata-se de uma história que fala da pobreza; trata-se de uma história pobre, sem artifícios.

Tais considerações levam-me de imediato ao romance Vidas secas, de Graciliano Ramos, em que a noção de falta e de carência que permeia a vida da família de Fabiano estende-se à linguagem (ou à falta dela, em alguns momentos cruciais da história), o que provoca no leitor não apenas a consciência sobre o drama da seca e de seus protagonistas mas a percepção sensorial e emotiva dessa realidade. Com A hora da estrela ocorre algo semelhante: a falta existe para preencher; tirar é proporcional ao fazer o texto explodir de sentidos.

Assim sendo, voltemos à pobreza que ronda a história de Macabéa, que entra no seu quartinho de periferia e dói no dente cariado do narrador. Logo no início, o narrador divaga sobre os muitos sentidos da pobreza: Se há veracidade nela - e é claro que a história é verdadeira embora inventada - que cada um a reconheça em si mesmo porque todos nós somos um e quem não tem pobreza de dinheiro tem pobreza de espírito ou saudade por lhe faltar coisa mais preciosa que ouro - existe a quem falte o delicado essencial (Lispector, 1984, p. 18). 
Reitere-se, nesse momento, que, ao falar sobre a pobreza, Clarice fala de algo que conheceu muito proximamente. Na biografia da escritora, Nádia B. Gotlib recorta a fala de Clarice, que declara: "Era pobre, muito pobre. Filha de imigrantes" (Gotlib, 1995, p. 69). E essa percepção sensível de pobreza ronda quase toda a obra clariceana, como se pode ler nos contos "Restos de carnaval" e "Felicidade clandestina", textos de inspiração nitidamente autobiográfica. Mas, na personagem Macabéa, a pobreza está associada à redução, à degradação, à desvalorização do ser, afetando-o na sua dignidade, como se lê no excerto:

Quero neste instante falar da nordestina. É o seguinte: ela como uma cadela vadia era teleguiada exclusivamente por si mesma. Pois reduzira-se a si. Também eu, de fracasso em fracasso, me reduzi a mim mas pelo menos quero encontrar o mundo e seu Deus (Lispector, 1984, p. 25).

Tanta inclemência deve-se ao propósito de desvendar engodos, à missão desmistificadora, que é da natureza do literário, e que revela o papel excludente das forças sociais. $\mathrm{O}$ "eu" que poreja na narrativa é uma consciente associação de personagens - Clarice, Rodrigo, Macabéa - que se debatem em busca de sentidos.

Há, em diversas partes do romance, a confissão de uma necessidade premente: "Pois tenho que tornar nítido o que está apagado e que mal vejo. Com mãos de dedos enlameados apalpar o invisível na própria lama" (Lispector, 1984, p. 25). O ato de "apalpar a lama" não distancia o leitor do processo genesíaco, do ato criador, e reafirma a ideia de que o assunto de que se vai tratar na narrativa não é matéria afeita ao mundo da limpeza e da assepsia: apresenta a pobreza tal qual Clarice a percebe - a pobreza enlameada, degradada, feia.

Antagonicamente o leitor é levado ao mundo de certa categoria de pobres que abunda na literatura. A pobreza maquiada pela decência, pelos impulsos de nobreza - "pobre, porém honesto" é um dos epítetos que se tira dessa tradição nem sempre afortunada - pelas prostitutas ingênuas e encantadoras, como as que estão, por exemplo, nos romances dos anos $1930^{2}$. Tal necessidade reafirma a escolha de Clarice por Rodrigo S. M. para se distanciar de Macabéa, de sua experiência de mulher. Mas é inegável que a estratégia a aproxima de sua própria história de vida, da família judia, que migra para o Brasil, da infância pobre no Nordeste e da

\footnotetext{
${ }^{2} \mathrm{O}$ romance de 30 , de inspiração nitidamente social, defende o proletário, o homem do povo alijado do sistema, mas sua linha narrativa é, não raramente, marcada pelas teorias marxistas e pela propaganda comunista. A prostituta idealizada aparece, por exemplo, nos romances de Jorge Amado.
} 
orfandade precoce ${ }^{3}$. Essas características foram decisivas à elaboração do romance A hora da estrela, tanto no plano da história narrada, que, segundo reitera Rodrigo S. M., é escrita com o corpo - "Eu não sou um intelectual, escrevo com o corpo" (Lispector, 1984, p. 22) - como nas técnicas de escrita utilizadas pela autora. Além disso, na "Dedicatória do autor (Na verdade Clarice Lispector)", há a revelação inevitável: "Dedico-me à saudade de minha antiga pobreza, quando tudo era mais sóbrio e digno e eu nunca havia comido lagosta" (Lispector, 1984, p. 7). Tal revelação incute ao leitor o desejo imediato de procurar traços dessa sobriedade e dignidade na história de Macabéa.

Retomando a comparação estabelecida com Vidas secas, questiona-se até que ponto Clarice Lispector recorre a estratégias da ironia e da burla, com o fim de levar seus leitores a experiências desusadas. No romance de Graciliano Ramos, as personagens e as ações pertencem a um sentido comum, que os prende e os nivela numa horizontalidade em que não há espaços para intervenções do narrador. É um narrador que privilegia a descrição com o mesmo olhar seco e bruto, sem lirismo, de modo a reiterar a sequidão do mundo que oprime os seres. Esse distanciamento não existe entre Rodrigo S. M. e sua personagem; ele se compromete com Macabéa, do início ao fim da história.

À primeira vista, poder-se-ia supor que, em Macabéa, é retirado aquele substrato humano essencial, próprio da complicação romanesca. Nesse personagem e no romance, a autora despe-se de uma visão feminina, como a querer dizer que pode escrever como os homens, conforme sugere um dos títulos do romance, "saída discreta pela porta dos fundos". Mas é também por esse romance que se pode afirmar que as leituras apressadas são sempre enganosas numa escritora como Clarice Lispector.

A precariedade que Macabéa carrega em seu corpo de moça virgem, em sua opacidade de mulher, em sua inconsciência como pessoa e na falta de apetite para a vida, reitera a pobreza que rói sua parca vidinha de nordestina na cidade grande. No entanto, por meio da exiguidade e da pobreza da moça, e que, afinal, alinhavam as páginas do romance, Clarice mofa dos lugares comuns, das previsibilidades da linguagem e das conclusões precipitadas. A técnica do empobrecimento, que aqui defendo como traço fundamental à construção desse romance, e que consiste em despojar de características a personagem e de efeitos a linguagem, desfere um golpe mortal na crença das oportunidades, prescrita nas formulações

\footnotetext{
${ }^{3}$ Conforme Nádia Batella Gotlib (1995) na biografia da autora, Clarice perde a mãe aos 9 anos de idade.
} 
liberais. E promove, por vias indiretas, a consciência daquele "delicado essencial" que poreja na ficção clariceana ${ }^{4}$.

Ainda que precariamente, Macabéa evoca um segredo que se guarda nas entrelinhas, um modo de compreender a vida que vem do corpo curvado pelo ofício de cerzideira, e boa cerzideira que era, e que vem de um súbito mal-estar de ter e ser esse corpo, como nas muitas passagens da obra em que a moça revela sentir-se enjoada: "Esqueci de dizer que às vezes a datilógrafa tinha enjoo para comer" (Lispector, 1984, p. 47); "Olhe, sangue eu não posso ver mesmo porque me dá vontade de vomitar" (Lispector, 1984, p. 65) e "No dia seguinte, segunda-feira, não sei se por causa do fígado atingido pelo chocolate ou por causa do nervosismo de beber coisa de rico, passou mal. Mas teimosa não vomitou para não desperdiçar o luxo do chocolate" (Lispector, 1984, p. 76).

Ao caracterizá-la como cerzideira, o narrador instaura desconfiança e provoca a aparente fixidez sobre a ideia de feiura, sujeira e despreparo que ronda Macabéa:

A moça tinha ombros de cerzideira. Aprendera em pequena a cerzir. Ela se realizaria muito mais se se desse ao delicado labor de restaurar fios, quem sabe se de seda. Ou de luxo: cetim bem brilhoso, um beijo de almas. Cerzideirazinha mosquito. Carregar em costas de formiga um grão de açúcar. Ela era de leve como uma idiota, só que não o era (Lispector, 1984, p. 33).

O trabalho delicado, minucioso, de "restaurar fios" contém um sentido mais elaborado de percepção de mundo, que se subtrai da inconsciência de si manifesta por Macabéa. Cerzir é juntar partes de um tecido que se esgarçou, é dar, pois, sentido e totalidade ao que se rompeu e perdeu visibilidade pela insistente rejeição que a civilização manifesta à pobreza. Afinal, como fica evidente nas páginas de $A$ hora da estrela, a pobreza é promíscua e anti-higiênica.

Cerzir é, também, o ofício que oferece contraponto ao ritmo alucinante e alienante da cidade grande; e é ofício dos pobres, que, alijados do fervor consumista do capitalismo, precisam ir remendando os "tecidos" que thes sobram na distribuição desigual de renda que alimenta o sistema. O ofício de cerzideira fomenta, ainda que indelevelmente, a ideia de que Macabéa, a personagem incompetente para a vida, tinha certa propensão para o labor produtivo e para produzir algum sentido em sua existência, embora

\footnotetext{
${ }^{4} \mathrm{Na}$ citação da quarta página deste estudo, ao falar da pobreza, em termos genéricos, o narrador alude à pobreza de quem tem ouro, mas a quem falta o "delicado essencial".
} 
Ivana Ferrante Rebello

a cidade grande a tenha forçado, tragicamente, a ser a má datilógrafa que trocava as letras e deixava nódoas de gordura nos papéis em que escrevia.

E quanto ao enjoo, esse mal-estar de estômago, proveniente, talvez, da escassez de alimentos a que a moça nordestina fora condicionada, desde criança, é outro traço decisivo na composição da personagem. Enjoar é rejeitar fisicamente o que as circunstâncias lhe reservam; é mal-estar físico, sinônimo do mal-estar que a vida provoca. Mas, durante toda a narrativa, Macabéa sustém o vômito; nos seus limites ela não encontra meios de colocar para fora a série de exclusões e rejeições a que é submetida, desde o berço. O impulso desse vômito vem somente no final, no instante de sua morte, conforme se lê no fragmento, mas não chega a se concretizar totalmente: "Nesta hora exata Macabéa sente um fundo enjoo de estômago e quase vomitou, queria vomitar o que não é corpo, vomitar algo luminoso. Estrela de mil pontas" (Lispector, 1984, p. 96).

Em sequência ao excerto, o narrador complementa que ela acaba por vomitar um pouco de sangue. Poder-se-ia suscitar os sentidos de catarse que a imagem do vômito contém, mas nessa história de moça nordestina, "que nem pobreza enfeitada tem", a vida não permite certas explosões. Só a morte. $\mathrm{O}$ vômito teria sido grandioso demais para Macabéa. A sina de Macabéa reitera o que disse Mário de Andrade acerca dos personagens deserdados na literatura. Para ele, "o fracassado" é um tipo de herói desfibrado, incompetente para viver, e que não consegue opor elemento pessoal algum, nenhum traço de caráter, nenhum músculo como ideal, contra a vida ambiente (Andrade apud Paes, 1990, p. 57). Entretanto, o pouco sangue expelido e a lembrança de que é tempo de morangos, revelada nas últimas linhas do romance, tinge de nódoa vermelha a história dessa moça insossa. E, sim, estamos aqui falando daquele "delicado essencial" que se cose à escritura clariceana. $\mathrm{O}$ vermelho dá cor e visibilidade à pobreza na sociedade, além de, claro, ter inegáveis conotações ideológicas.

Desde o início o leitor é levado a crer que a falta e a carência são artifícios imprescindíveis para se compor a história de Macabéa. A desumanização da moça pobre vem como notação irônica de sua própria liberdade, uma falsa liberdade, característica dos deserdados que são reprimidos e que morrem sozinhos: "Era apenas fina matéria orgânica. Existia. Só isto. E eu? De mim só se sabe que respiro" (Lispector, 1984, p. 47). Esse cuidado é exercitado também no plano da linguagem, que, em todo momento, sofre policiamento do narrador, que não quer cair em excessos, não quer mitificar ou estereotipar a pobreza, levando o leitor às lágrimas ou à comoção: 
Mas não vou enfeitar a palavra pois se eu tocar no pão dessa moça esse pão se tornará em ouro - e a jovem (ela tem dezenove anos) e a jovem não poderia mordê-lo, morrendo de fome. Tenho então que falar simples para captar a sua delicadeza e vaga existência. Limitome humildemente - mas sem fazer estardalhaço da minha humildade - limito-me a contar as fracas aventuras de uma moça numa cidade toda feita contra ela (Lispector, 1984, p. 21, grifo nosso).

A decisão de "não enfeitar a palavra" parece ilustrar o equilíbrio técnico e a limpidez estrutural que há no romance $A$ hora da estrela. Por um lado, ao renegar a visão sentimentalizada, Clarice Lispector aproxima-se gravemente da questão do pobre, do nordestino e do marginalizado na cidade grande. Por outro lado, conforme já sugerido nas comparações feitas com o romance Vidas secas, uma obra-prima do gênero, a escritora também não sucumbe à tendência realista de grande parte dos romances de cunho social e engajado, embora a opção por dar voz a Rodrigo possa fazer supor isso, a princípio. Com a delicadeza das escritoras cerzideiras e nesse aspecto reforçamos a identidade entre Clarice Lispector e Macabéa - ela consegue aliar, num mesmo corpo oco de moça, a plenitude de uma carência sem limites, doída para os que a sentem, atordoante para os alimentados que a leem.

A opacidade que a escritora põe sobre Macabéa acaba por potencializar a personagem, naquilo que ela traz de fundamental: a falta, o nada, a pobreza. Às vezes, esse "nada" ronda os limites da saturação em Macabéa: "Quando rezava conseguia um oco de alma - e esse oco é o tudo que posso eu jamais ter. Mais do que isso, nada. Mas o vazio tem o valor e a semelhança do pleno" (Lispector, 1984, p. 20). Como o narrador, ao cabo da leitura dessa história, ficamos ocos de Macabéa, ocos de sua pobreza e de sua insignificância. E essa é uma estratégia de que a autora faz uso para reafirmar o poder corrosivo do sistema sobre os fracos, os pobres e os marginais de toda sorte.

Se - retomando-se aqui, novamente, a comparação com Vidas secas Graciliano Ramos concebe, no seu romance, o sentido máximo da marginalização, em $A$ hora da estrela, o enredo reitera a ideia plena da nulidade. A subtração imposta aos marginais de Vidas secas ainda assim afirma uma situação antagônica, subliminar, que é a de que as águas, a fartura, a mudança de regime podem atenuar os efeitos desastrosos de tamanha desvalia. Tais atenuantes não se leem no romance de Clarice Lispector: suas páginas sem descanso, em que não se vê a pausa programática da ordem capitular, reforçam a realidade sem escapatória que ronda Macabéa, como a sugerir que, para a autora, não se pode vislumbrar redenção 
possível. A personagem Macabéa não é objeto da ficção engajada, é uma personagem marcada pelo sentido absoluto da perplexidade. $\mathrm{O}$ narrador, com livre acesso à intimidade da personagem, pouco ou nada extrai de seu interior. Nem o mundo, nem a literatura podem articular uma saída possível a essa pobreza avassaladora.

Desde o início da leitura, verifica-se que não há elementos no romance que afastem o leitor da dupla tragédia que se abate sobre a história; nos interstícios das palavras pressentimos a morte anunciada de Macabéa e de seu narrador, como a sugerir que a morte dessa personagem pudesse arrastar consigo a morte da própria narrativa, ou de uma tradição de narrar. São palavras, imagens e signos que traem o medo que ronda Rodrigo S. M. e Clarice Lispector: verbos predominantemente no tempo presente, como se a existência das palavras se prendesse à efemeridade do agora; ausência de passagens descritivas, o que reitera a ideia da pobreza sem enfeites; a luta do narrador contra os devaneios, tentando se ater aos fatos, ao empírico; a "in-corporação" da personagem pelo narrador, reiterando a tensão permanente que se instala entre ambos.

A personagem deficiente para a vida provoca a linguagem "deficiente" da narrativa, mas é aí que reside a maior eficiência do romance. "Que não esperem, então, estrelas no que se segue: nada cintilará, trata-se de matéria opaca e por sua própria natureza desprezível para todos" (Lispector, 1984, p. 22), adverte o narrador, no início da história.

Nesse conjunto de estratégias, não se pode deixar de mencionar que, por todo o romance, persiste uma espécie de lucidez zombeteira que escapa à voz de Rodrigo S. M. e, por ricochete, vai até Clarice. Os muitos títulos propostos para a história de Macabéa revestem-se da mais pura ironia da autora sobre o que a tradição literária estabelece. Se Macabéa é a antítese do personagem denso, complexo e heroico, a narrativa que lhe dá existência anula, em todos os seus pressupostos, a tradição do romance, porque põe desconfiança sobre o título, sobre a autoria, sobre as representações e sobre o papel da narrativa na modernidade. Ela antecede algumas teorias sobre o romance moderno que viriam a porejar na crítica literária a partir da década de 1980. E, consequentemente, abre espaço para outra escrita, que seria popularizada nos anos 1990 e se arrasta aos primórdios do terceiro milênio, como se comprova, aqui no Brasil, por exemplo, com Bernardo de Carvalho e Milton Hatoum, cujas características vão da multiplicidade de vozes narrativas à atribuição de um sentido de performer 5 às suas escritas.

\footnotetext{
${ }^{5}$ Nesse caso, refiro-me à expressão utilizada por Beatriz Rezende, em Contemporâneos: expressão da literatura brasileira no século XXI (2008). Para ela, "performers" são os autores que revelam suas personalidades literárias nas obras.
}

228 est. lit. bras. contemp., Brasília, n. 41, p. 219-232, jan.jun. 2013 
Em "As novas narrativas" ([1979] 1987), Antonio Candido localiza, na produção literária dos anos 1970, o que ele denomina de "realismo feroz", de que são representantes autores como João Antonio e Rubens Fonseca. Segundo o crítico, o fato de que a maior parte das narrativas utiliza o ângulo da primeira pessoa faz com que a brutalidade do meio urbano seja transmitida pela brutalidade de seu agente (ou personagem). Quando o escritor substitui a primeira pessoa do discurso pela terceira, segundo Candido, perde-se a força expressiva do texto, podendo surgir, a partir daí, um exotismo de tipo especial, que pode soar ao leitor de classe média como pitoresco.

Esse é um conflito que se manifesta explicitamente nas páginas de A hora da estrela, embora a primeira pessoa esteja ali a gritar surdamente. A narrativa do romance movimenta-se em estado de permanente tensão, decorrente da dificuldade expressa pelo narrador - elitizado, alimentado e portador de instrumental sofisticado de linguagens - para representar essa nordestina pobre e "subletrada", conforme se lê: "Não, não é fácil escrever. É duro como quebrar rochas. Mas voam faíscas e lascas como aços espelhados" (Lispector, 1984, p. 25). Por trás dessa dificuldade, em que se pressente a percepção muito aguda da autora de seu próprio papel de intelectual e sua condição contraditória numa sociedade cheia de problemas, há uma necessidade de dar voz aos desvalidos.

No plano da narração não há nada que sintetize tão bem esse estado de tensão como a relação de Macabéa com a Rádio Relógio, que dava "hora certa e cultura, e nenhuma música" (Lispector, 1984, p. 45). Ao se nutrir da inutilidade das informações diárias colhidas, Macabéa tenta se instrumentalizar precariamente, a fim de sobreviver na sociedade de desiguais, mas por não entender as notícias e por não ter acesso à música - a arte poderia ser uma escapatória, uma via de acesso à libertação -, ela sucumbe. O não sentido das notícias da Rádio enfraquece o caráter individual das experiências; e a repetição marca a ideia de circularidade inescapável.

Também se vê, sempre pela via da ironia, como a personagem tenta pertencer à modernização da cidade e ter acesso aos bens do capitalismo: Macabéa fazia coleção de anúncios. Os produtos ofertados pela sociedade, inacessíveis à moça pobre, chegam a ela pela forma do desejo mal formulado e distorcido, pois Macabéa sente vontade de comer um creme destinado à pele de "mulheres que simplesmente não eram ela" (Lispector, 1984, p. 46).

Escrever sobre a pobreza aguda, e plurissignificativa, que caracteriza o Brasil de seu tempo (tempo não muito diferente do de hoje), provoca faíscas de "espelhos", nas quais o escritor pensa e traduz o mundo, mas 
onde também se vê refletido. "Os fatos são sonoros, mas entre os fatos há um sussurro" (Lispector, 1984, p. 31), lembra-nos o narrador. A ciência de que a linguagem sonoriza a vida, mas não é suficiente para captar os sussurros, parece conduzir a autora para uma única saída possível: a opção

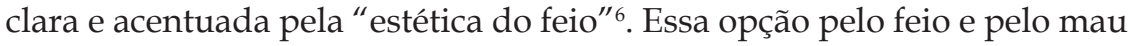
gosto parece orientar a escritora em suas últimas obras, como $A$ hora da estrela e a Via crucis do corpo.

Vilma Arêas (1979) distingue a obra de Clarice Lispector em duas fases: a "literatura das entranhas" e a "literatura da ponta dos dedos", nas quais situaria esses últimos romances. Neles, o leitor encontrará, segundo Arêas, uma Clarice comprometida de forma mais explícita com os problemas sociais do mundo. Sou, nesse ponto da discussão, forçada a dizer que, em A hora da estrela, a ponta dos dedos provoca a revolução das entranhas; e esta é obrigada, afinal, a expelir um resto de sangue.

Macabéa distancia-se da figura do pobre malandro, popularizada pelo tipo de Leonardo Pataca, de Memórias de um Sargento de Milícias; não tem a dignidade muda de um Fabiano, de Vidas secas, cuja marca de exceção está nas costelas magras e na ausência de voz; tampouco celebra a vida ossuda e dividida como o Severino retirante, de João Cabral de Melo Neto.

Se, em Olímpio, o namorado nordestino de Macabéa, pode-se vislumbrar certo traço da fraca esperteza - que não é senão a reação mais visível do desvalido para com o sistema que o oprime -, o que sobressai nele, e verdadeiramente, é a distorção grotesca, o rebaixamento risível que ostenta, desde seu nome pomposo - que não é senão a risada da autora sobre a estética clássica, figurativa - até sua opção pela "carnuda" Glória, estereótipo da hipertrofia sexual atribuída por parcela de literatos à mulher pobre.

Essa literatura autorreflexiva afasta-se do ideal clássico de imitação para ser uma distorção; ao invés de ser uma figuração de mundo, como pretendia Rodrigo S. M., passa a ser uma "configuração"7. Macabéa "configura" essa pobreza, porque é suja, burra, rala e inocente. Tudo que a rebaixa, desumaniza e degrada parece, por outro lado, também exaltá-la, porque ela sintetiza, no seu corpo frágil, a aporia que paralisa o intelectual, a consciência da inutilidade das ideologias e a enorme impiedade que se abate sobre os fracos. As muitas Marias - todas as colegas de quarto de Macabéa chamam-se Maria - parecem espectros que se cosem insistentemente ao romance clariceano. A vida da cidade prossegue inalterada, a

\footnotetext{
${ }^{6}$ Segundo Sônia Roncador (2002), Clarice abandona, em suas últimas obras, a forma elegante que a caracteriza para adotar uma estética do feio, produzindo obras deliberadamente de mau gosto.

${ }^{7}$ Configurar: dar forma ou figura de, conformar. Dicionário de Língua Portuguesa, 1986, p. 451.
} 
despeito da fome e das Marias que se espremem nos cortiços, relegadas a uma dolorosa periferia.

Sobretudo, é preciso nunca esquecer que Macabéa-Rodrigo-Clarice constitui uma tríade indissociável, uma projeção de iguais, que os lança na mesma atmosfera de desencanto. Reporto, mais uma vez, aos ombros curvos de cerzideira, que constituem os ombros daqueles que se põem a remendar os retalhos do mundo. É um labor de esteta, porque os pontos do cerzir são emendados uns nos outros, perfeitamente encadeados e quase invisíveis, tais quais os textos que seduzem pela harmonia, pelo teor de dramaticidade ou pela leveza que trazem. Como a personagem Macabéa, o escritor (escritora) já não pode cerzir. O mundo, a vida, a sociedade transforma-nos - pois também o leitor se vê nesses espelhos - na datilógrafa pobre e incompetente.

A morte de Macabéa não pode deter o ritmo da cidade, como não pode deter o ritmo da vida e da morte, que pertence ao inexorável. Restanos, como o narrador, acender um cigarro e "não esquecer que por enquanto é tempo de morangos. Sim" (Lispector, 1984, p. 98). De repente, a delicadeza aguda dos morangos fere o cotidiano magro e faminto.

Este é um romance todo de negações, mas começa e termina com um "sim". Essa seria a insustentável estrela, a dolorosa palavra, de Clarice Lispector?

\section{Referências}

ARÊAS. Vilma (1997). Con la punta de los dedos. Anthropos, Barcelona, extra 1 e 2, p. 68-72

CANDIDO, Antonio (1993). O discurso e a cidade. São Paulo: Duas Cidades. p. 19-54.

. ([1979]1987) A nova narrativa. In: A educação pela noite e outros ensaios. São Paulo: Ática. p. 199-215.

GOTLIB, Nádia Batella (1995). Clarice: uma vida que se conta. São Paulo: Ática.

LISPECTOR, Clarice (1984). A hora da estrela. 9. ed. Rio de Janeiro: Nova Fronteira. OLIVEIRA, S. Ribeiro de (1985). A barata e a crisálida: o romance de Clarice Lispector. Rio de Janeiro: José Olympio; Brasília: INL.

PAES, José Paulo (1999). O pobre diabo no romance brasileiro. In: A aventura literária: ensaios sobre a ficção e ficções. São Paulo: Companhia das Letras.

REZENDE, Beatriz (2008). Contemporâneos: expressão da estética brasileira do século XXI. Rio de Janeiro: Casa da Palavra.

RIBEIRO, Leo Gilson (1977). A hora das estrelas. Jornal da Tarde, São Paulo, p. 19. RONCADOR, Sônia (2002). Poéticas do empobrecimento: a escrita derradeira de Clarice. São Paulo: Annablume.

SANTOS, Joel Rufino dos (2004). Os pobres. In: Épuras do social: como podem os intelectuais trabalhar com os pobres. São Paulo: Global. 
Ivana Ferrante Rebello

Recebido em maio de 2012.

Aprovado em outubro de 2012.

\section{resumolabstract}

Sobre restaurar fios: reflexões sobre a pobreza em A hora da estrela

Ivana Ferrante Rebello

Este artigo lê o romance A hora da estrela, de Clarice Lispector, sob o fulcro da pobreza. Sob a história da nordestina pobre e fracassada para a vida cola-se uma escrita angustiada e autorreflexiva, metaforizada, no plano da narrativa, no ofício de cerzir, interrompido, e na prática deficiente de datilógrafa de Macabéa. A pobreza sem enfeites é recurso da autora para colocar em cena sua impotência de escritora.

Palavras-chave: Clarice Lispector, A hora da estrela, pobreza, autorreflexão.

\section{About restoring wires: reflections on poverty in A hora da estrela}

Ivana Ferrante Rebello

This article reads the novel A hora da estrela, by Clarice Lispector, through the lens of poverty. The story of a poor northeast girl and without success in life is an anguished and self-reflective narrative. The job of darning and typing are metaphors of the tension of the author. The novel about poverty brings into the scene the impotence of writing about the events.

Keywords: Clarice Lispector, A hora da estrela,_poverty, self-reflection. 